\title{
Development of Script-Based Auditory Training and Preliminary Evaluation of the Training Efficacy for Young Adults with Cochlear Implants
}

\author{
Da Jung Yun', Hui Won Bae², Jin Kim³, Youngmee Lee ${ }^{4}$ \\ 'Department of Audiology, Hallym University of Graduate Studies, Seoul, Korea \\ ${ }^{2}$ Dr. Park Sung-II Audiologic habilitation Center, Busan, Korea \\ ${ }^{3}$ Haeundaegu Multicultural Family Support Center, Busan, Korea \\ ${ }^{4}$ Department of Communication Disorders, Tongmyong University, Busan, Korea
}

\section{인공와우이식 청년의 의사소통 능력 향상을 위한 스크립트 기반의 청능훈련 도구 개발 및 효과에 대한 예비평가}

\author{
윤다정 $\cdot$ 배희원 ${ }^{2} \cdot$ 김 진 $^{3} \cdot$ 이영미 ${ }^{4}$ \\ 한림국제대학원대학교 청각학과 ${ }^{4}, \mathrm{Dr}$. 박성일 청각재활센터 ${ }^{2}$, 해운대구 다문화 가족지원센터 ${ }^{3}$, 동명대학교 언어치료학과 ${ }^{4}$
}

\begin{abstract}
Purpose: The purpose of the current study was to develop the script-based materials for auditory training and to investigate the effects of script-based auditory training for congenitally deaf young adults with cochlear implants (CIs). Methods: A total of eight scripts were developed based on the literature review and the survey for speech-language pathologists, adults with normal hearing (NH), and adults with Cls. For validation of the materials, words and sentences of auditory training tool were examined using the four-point Likert scale by 35 adults with $\mathrm{NH}$, and words and sentences below 2 point were removed and replaced from the script. For evaluating the efficacy of the training, three adults with Cls attended the auditory training individually, two times per a week for 4 weeks. Their speech recognition skills and subjective communicative satisfaction were evaluated before and after auditory training, and analyzed using a onegroup pretest and posttest design. Results: Although there were not significant increases in the speech recognition scores at the word and sentence level, there were significant increases in the overall communicative satisfaction on the results of the questionnaire. Conclusion: The current study suggests that auditory training using the script-based materials is useful in improving overall communicative satisfaction for young $\mathrm{Cl}$ users who have limited communication skills.
\end{abstract}

Key Words: Script-based auditory training, Congenital-deaf adults, Cochlear implants.

Received: April 24, 2018 / Revised: June 18, 2018 / Accepted: October 2, 2018

Correspondence: Youngmee Lee, Department of Communication Disorders, Tongmyong University, 428 Sinseon-ro, Nam-gu, Busan 48520, Korea

Tel: +82-51-629-2135 / Fax: +82-51-629-2019 / E-mail: ymlee3060@gmail.com

\section{INTRODUCTION}

2015년도 장애인 실태조사에 따르면, 국내 난청인의 수는 약 28만 명으로 추정되며(Statistics Korea, 2015), 그 수가 지속적 으로 증가하고 있다. 세계보건기구[World Health Organization (WHO), 2018]에서는 전 세계의 약 6억6천 6백만 명의 사람들

(c) This is an Open Access article distributed under the terms of the Creative Commons Attribution Non-Commercial License (https://creativecommons.org/licenses/by-nc/4.0) which permits unrestricted non-commercial use, distribution, and reproduction in any medium, provided the original work is properly cited.
이 청력 손실을 겪고 있으며, 2050년까지 약 9억 명 이상이 난 청인으로 어려움을 겪을 것으로 예상한다고 보고하였다. 또한, $\mathrm{WHO}$ (2018)에서는 여가와 취미 활동에서 발생되는 소음으로 인해 청소년과 성인이 후천적으로 청력 손실을 경험할 수 있다 고 보고하였다. 난청의 발생 시기 및 원인에 상관없이 난청 성 인은 상대자의 발화를 제대로 이해할 수 없는 문제에 직면하게 되며, 건청 성인과의 의사소통에 어려움을 경험한다. 난청 성인 의 수가 지속적으로 증가되는 현재의 상황을 고려해 볼 때, 난청 성인이 겪는 의사소통의 어려움은 개인 문제가 아니라 사회적인 
문제로 인식할 필요가 있다.

청각 손실로 인한 의사소통장애는 우울증, 사회적 고립, 외 로움, 삶의 질 저하 등을 초래하므로, 청능훈련은 난청 성인의 사회적 참여 증대와 삶의 질 향상에도 초점을 맞추어야 한다 (Yorkston et al., 2010). 즉, 난청 성인의 의사소통 단절을 최소 화하고 독립적인 삶을 영위하도록 개인의 요구(needs)와 청력 특성에 적합한 청능훈련 프로그램을 개발하고 계획할 필요가 있는 것이다. Sweetow \& Sabes(2006)는 의사소통 전략훈련 (communication strategies training), 독화훈련(speech reading training), 인지적인 능력을 강화하는 훈련 등으로 난청 성 인의 전반적인 의사소통 능력을 향상시킬 수 있다고 하였으며, Blamey \& Alcántara(1994)는 보장구를 통해 지각되는 청각 정 보의 양을 증가시켜서 난청인의 전반적인 의사소통 능력을 향상 시켜야 한다고 하였다. 국내외에서 난청 성인의 청능훈련의 필요 성과 훈련 방법에 대한 관심이 높아지면서, 다양한 접근법을 이 용하여 난청 성인의 청능훈련의 효과에 관한 연구 결과가 보고 되고 있다. Lee et al.(2016)은 보청기 착용만으로도 말 인지도가 낮은 난청 성인 $(\mathrm{n}=2)$ 에게 10 주 동안의 청능훈련을 실시하였으 며, 그 결과 환경음, 단어, 문장 인지도 측면에서 모두 향상되었 으며, 주관적인 난청지수도 함께 감소하였다고 보고하였다. Song(2008)이 인공와우이식 성인 $(\mathrm{n}=3)$ 을 대상으로 소음 상황 에서 4주 동안 청능훈련을 실시한 결과에서도 단어 및 문장 지 각 능력의 향상을 보고하였다. Burk et al.(2006)은 보청기를 부 분 착용(part-time use)하는 경도-중등도의 난청 노인 $(\mathrm{n}=7)$ 을 대상으로 소음 상황에서의 청능훈련을 실시한 결과, 청능훈련 후에 훈련 단어와 비훈련 단어 모두에서 청각적 수행력이 건청 성인 $(\mathrm{n}=16)$ 만큼 향상되었다고 보고하였다. 그리고 $\mathrm{Fu}$ et al. (2005)이 인공와우를 착용한 성인 $(\mathrm{n}=10)$ 에게 컴퓨터를 이용한 재택형 청능훈련을 1 개월 동안 실시한 결과에서도 난청 성인의 어음인지 능력 향상에 도움이 된다는 것을 확인하였다. 이러한 난청 성인의 청능훈련의 긍정적인 결과 보고에도 불구하고, 임 상 현장에서는 다양한 청능훈련 도구가 부족하여 난청 성인에 게 체계적으로 청능훈련을 실시하기가 어려운 실정이다(Baek $\&$ Lee, 2016).

일반적으로 난청 성인은 적절한 보장구를 착용하는 것만으 로도 의사소통 능력이 개선되기도 하지만, 의사소통 능력을 극 대화시키기 위해서는 능동적인 학습을 유도할 수 있는 개별화 된 청능훈련이 필요하다(Oh, 2016). 효과적인 청능훈련 프로토 콜은 대상자의 개별 요인(예, 보장구 착용 상태에서의 가청력, 인 지 능력 등)과 언어자극 등을 고려하여 대상자 맞춤식 청능훈 련 도구와 자료로 활용될 수 있도록 개발되어야 한다. 이러한 청능훈련 프로토콜 프레임에 따라 최근에는 난청 성인의 청능 훈련 도구 개발 및 중재 효과에 관한 연구 보고가 발표되고 있
다. 국내 연구를 중심으로 살펴보면, 환경음을 이용한 청능훈 련 도구(Ahn \& Lee, 2016), 가로세로 단어판과 같이 게임을 매 개로 한 청능훈련 도구(Baek \& Lee, 2016), 이야기를 이용한 청능훈련 도구(Kim \& Bahng, 2017; Lim \& Bahng, 2016)가 개발되었다. 이러한 청능훈련 도구는 난청 성인의 말지각 개선 에 긍정적인 효과를 보고하였으며, 저자들은 난청 성인의 개별 적인 특성과 요구를 고려한 다양한 청능훈련 도구 및 자료의 개 발이 필요하다고 언급하였다.

청각재활전문가는 난청 성인이 다양한 의사소통 문맥(context)에서 자신감을 가지고 의사소통을 할 수 있도록 의사소통 기회를 증대시키고 습득한 기술을 일반화할 수 있도록 다양한 접근법을 모색할 필요가 있다. 즉, 난청 성인이 일상생활에서 필요한 의사소통 기술을 우선적으로 습득하고, 주변 의사소통 에서 겪는 제한성과 방해 요소를 최소화하기 위한 기능적인 접 근법(functional approach)을 청능훈련에 적용할 필요가 있다. 언어병리학 분야의 연구자들은 기능적인 의사소통 능력을 향 상시키는 효과적인 중재 방법으로 스크립트(script)를 주목한 바 있다(Kim, 2014). Kim(2014)은 스크립트를 “즉각적으로 일 상 상황에 대하여 화자 간에 공유하는 상황지식을 제공해 주며, 상황에서 늘 사용되는 상황언어를 배우는 학습의 기회를 제공 해준다"라고 언급하였으며, 대상자에게 실제 익숙하고 일상화 된 맥락을 대본으로 구성하고 적합한 소도구 이용과 시연을 통 하여 적극적인 언어 중재를 할 수 있다고 하였다. Lemke \& Scherpiet(2015)는 난청인이 속한 사회적 맥락(social context) 에서의 구어 의사소통 능력을 토대로 사회 참여 양상을 살펴보 는 생태학적 관점(ecological view)이 청각재활 분야에서도 필 요하다고 하였다. 스크립트 기반의 청능훈련은 난청 성인의 생 태학적 의사소통 맥락을 고려한 접근법으로, 반복적인 사회적 맥락에서 경험하는 의사소통 상황에서 대상자의 언어 표현 능 력과 상황 예측 능력을 학습시켜줄 수 있는 기능적인 접근법이 라 할 수 있다.

스크립트 접근법은 선천성 농(congenital deafness)으로 인 해 제한적인 의사소통 능력을 지닌 성인이 지역사회 참여에 필 요한 다양한 문장을 익히는 데 유용할 것으로 생각된다. 선천성 농 성인은 영유아기와 아동기에는 제한된 듣기 경험으로 원활 한 말, 언어 발달에 어려움을 겪으며, 청소년기와 청년기에는 낮 은 의사소통 능력으로 인해 대인관계 확장, 진로 결정, 취업 등 에 제약이 따른다(Lee et al., 2018). 국내에서는 2000년 이후의 인공와우이식 성인에 관한 연구는 매우 미비하여(Cho et al., 2011), 선천성 농의 젊은 성인을 대상으로 한 Choi et al.(2018), Lee et al.(2011), Lee et al.(2018)의 연구에 그치고 있다. Lee et al.(2018)의 연구에 따르면, 아동기에 인공와우이식을 받은 선천 성 농의 젊은 성인의 경우, 인공와우이식 연령, 잔존 청력, 청력 
박탈 기간, 인공와우 사용 기간, 듣기 능력, 말명료도, 언어지식, 재활 여부와 같은 요인들이 의사소통 능력에 영향을 미쳤다. 이 처럼 다양한 요인이 인공와우이식 선천성 농 성인의 의사소통 능력에 영향을 미치기 때문에, 이들은 토털커뮤니케이션(total communication)으로 의사소통을 하는 수준부터 구어 의사소 통이 원활한 수준까지 개인 간에 의사소통 능력 차이가 큰 집 단이라 할 수 있다. 의사소통 능력이 영유아기부터 성인기까지 의 오랜 기간 동안 성장 과정 중에서 지속적으로 이루어지는 것을 감안할 때, 제한적인 의사소통 능력을 지닌 인공와우이식 선천성 농의 젊은 성인의 청능훈련에는 스크립트와 같은 일상 생활과 밀착된 문장 및 어휘를 익숙하게 하는 기능적인 접근법 이 필요하다고 할 수 있겠다.

스크립트 중재의 효과를 보고한 다수의 연구(Cho \& Kim, 2014; Kim et al., 2011; Kim \& Choi, 2013; Shim, 2012)들은 주 로 발달장애 아동을 대상자로 한 것으로, 저자들은 스크립트 중재가 보완대체 의사소통(augmentative and alternative communication), 사회극(role play) 등과 같은 접근법과 접목이 쉬 워서 의사소통 능력 발달에 긍정적인 영향을 미친다는 점을 강 조하였다. 스크립트를 난청인에게 적용한 연구(Lee, 2004; Lee et al., 2013)를 살펴보면, 주로 인공와우이식 아동을 대상으로 한 것으로 언어 이해 및 표현에 긍정적인 효과가 있는 것으로 보고되었다. Lee(2004)가 스크립트 접근법을 인공와우이식 아 동 $(\mathrm{n}=2)$ 에게 적용한 결과, 문장 표현, 자발화 개시, 언어 표현 능력이 향상되는 결과를 확인하였다. Lee(2008)가 보청기나 인 공와우를 착용한 아동 $(\mathrm{n}=8)$ 에게 스크립트 활동을 이용하여 중재한 결과에서도 중재 후의 명사와 동사의 이름대기 능력이 중 재 전에 비해서 유의하게 향상되었다고 보고하였다. Lee et al.(2013)이 중도 복합장애를 지닌 인공와우이식 아동 $(\mathrm{n}=5)$ 에게 스크립트 활동을 적용한 보완대체 의사소통 중재를 실시한 결과 에서도 발성, 제스처, 단어와 같은 의사소통 행동이 유의하게 증 가되었다. 선행연구 결과를 토대로 볼 때, 스크립트 중재는 아동 뿐만 아니라 제한적인 의사소통 능력을 지닌 인공와우이식 성인 이 타인과 상황지식을 공유하게 하여 의사소통 능력을 향상시키 는 데 효과가 있을 것으로 생각된다.

청능훈련은 언어의 다양한 말소리를 인식하는 상향식 접근 법(bottom-up approach)과 이야기의 흐름 속에서 음소를 유 추하는 하향식 접근법(top-down approach)으로 진행될 수 있 다(Kim et al., 2014). 늦은 시기에 인공와우이식을 받은 선천성 농 성인의 경우, 오랜 기간 동안의 청력 손실로 인해 의사소통 에서 겪는 어려움이 크다는 것을 고려할 때, 이들이 일상생활에 서 겪는 상황을 재연하고 경험하게 하는 하향식의 종합적인 청 능훈련 도구가 필요하다. 또한, 시연과 소도구를 이용하는 스크 립트 기반의 청능훈련은 인공와우를 착용한 선천성 농의 젊은
성인이 흥미를 가지고 능동적으로 청능훈련에 참여하는 데 도 움을 줄 수 있을 것이다. 이에 따라, 본 연구에서는 인공와우이 식 선천성 농 성인에게 일상생활과 밀접한 고빈도 어휘와 문장 을 반복적으로 청취하고 대화를 원활히 할 수 있도록 스크립트 기반의 청능훈련 도구를 개발하고, 스크립트를 이용한 청능훈 련의 효과를 검증하기 위해서 인공와우이식 선천성 농 성인에 게 4주간의 청능훈련을 실시하여 청각적 수행력과 주관적인 의 사소통 만족도의 변화를 살펴보고자 하였다.

\section{MATERIALS AND METHODS}

\section{1단계: 스크립트 상황 선정}

청능훈련 도구에 사용할 스크립트는 난청 성인에게 친숙하 면서 어려움을 겪을 것으로 예상되는 장소와 관련된 상황으로 구성하였다. 스크립트 선정을 위하여, 문헌조사 및 전문가, 건 청 성인 및 인공와우이식 성인을 대상으로 한 설문조사를 실시 하였다. Park(2008)의 지역사회 중심 스크립트를 참고하여 20 30대 일반 성인이 자주 이용하는 지역사회 상황을 발췌하 였으며, 현재 언어재활사 1 급 자격증을 소지하고 있으며 청능훈 련 전문기관에서 1 5년의 임상 경력을 가지고 있는 언어재활사 $(\mathrm{n}=5)$ 에게 난청 성인의 청능훈련에 유용하고 필요한 스크립 트 상황에 대한 인터뷰를 실시하였다. 그 결과, 버스, 병원, 약 국, 음식점, 지하철, 은행, 미용실, 옷 가게, 마트, 도서관, 극장, 패스트푸드점, 공중목욕탕, 공공시설과 같이 총 14 개 장소와 관련된 스크립트가 1차적으로 선정되었다.

선정된 스크립트가 일상생활에 실제로 빈번하게 접하는 상 황인지 확인하기 위해서, 현재 대학생, 아르바이트생, 직장인으 로 활동하고 있는 20대 건청 성인 67 명 $(\mathrm{M}=23.1, \mathrm{SD}=1.47)$ 을 대상으로 네이버 오피스 폼(Naver office form) SNS 매체를 이 용하여 설문조사를 실시하였다. 그 결과, 영화관(30\%), 노래방 (21\%), $\mathrm{PC}$ 방(19\%)과 같이 취미 및 여가생활과 관련된 상황이 실제로 많이 접하는 상황으로 나타났다(Table 1). 조사에서 많 이 활용하는 장소로 선정된 장소 중에서 $\mathrm{PC}$ 방과 노래방의 경 우, 의사소통보다는 개인 활동이 중심이 되는 점을 고려하여 스 크립트 선정에서 제외하였다. 그 결과, 총 12 개의 장소(도서관, 마트, 회사, 병원, 대중교통, 카페, 음식점, 대학교, 영화관, 은행, 미용실, 옷 가게)가 선정되었다. 그리고 난청 성인이 일상생활에 서 자주 접하면서 의사소통에 어려움을 경험하는 스크립트를 선정하기 위하여, 인공와우를 착용한 20대 성인 20 명 $(\mathrm{M}=$ $21.95, \mathrm{SD}=1.79)$ 을 대상으로 건청 성인의 설문조사 방법과 동 일한 SNS 매체를 이용하여 설문조사를 실시하였다(Appendix 1). 설문 문항은 해당 장소 관련 상황이 빈번하게 접하는 정도 와 어려움을 느끼는 정도와 관련된 것으로 중복 응답이 가능 
하도록 구성하였다. 그 결과, 자주 접하는 장소는 대중교통 (42.5\%), 마트(27.5\%), 영화관(15\%) 순이었으며, 의사소통 시 어 려움을 느끼는 장소에는 미용실(45\%), 은행(35\%), 병원(15\%), 옷 가게(5\%) 순서로 나타났다(Table 2). 그 후, 인공와우이식 선천 성 농의 청년 2명을 대상으로 인터뷰를 실시하여 스크립트 상황 을 선정하였다. 이때, 의사소통 상황이 유사한 마트와 편의점, 음식점과 카페 중에서, 인터뷰 내용을 토대로 마트와 카페를 스 크립트 상황으로 정하였다. 최종적으로 난청 성인의 의사소통

Table 1. Frequency (\%) of script for developing auditory training materials in young adults with normal hearing $(n=67)$

\begin{tabular}{|c|c|c|}
\hline Category & Situation of script & Frequency (\%) \\
\hline \multirow[t]{6}{*}{ Leisure } & Cinema & $20(30)$ \\
\hline & Karaoke & $14(21)$ \\
\hline & PC room & $13(19)$ \\
\hline & Playground & $12(18)$ \\
\hline & Billiard room & $7(10)$ \\
\hline & No response & $1(2)$ \\
\hline \multirow[t]{14}{*}{ Community facilities } & Mart & $13(19)$ \\
\hline & Convenient store & $11(16)$ \\
\hline & Restaurant & $8(12)$ \\
\hline & Café & $7(10)$ \\
\hline & Clothing store & $7(10)$ \\
\hline & Bank & $6(9)$ \\
\hline & Public transportation & $4(6)$ \\
\hline & Library & $4(6)$ \\
\hline & Hospital & $2(3)$ \\
\hline & Beauty shop & $2(3)$ \\
\hline & $\begin{array}{l}\text { Pharmacy, cosmetic shop, } \\
\text { shoe store }\end{array}$ & $1(2)$ \\
\hline & Cosmetic shop & $1(2)$ \\
\hline & Shoe store & $1(2)$ \\
\hline & Local resident center & $0(0)$ \\
\hline
\end{tabular}

능력 증진을 위한 스크립트 제작을 위하여 8개 장소(미용실, 영 화관, 옷 가게, 마트, 카페, 병원, 은행, 대중교통)를 선정하였다.

\section{2단계: 스크립트 제작}

연구자들은 2017년 7월 24일부터 8월 11일까지 스크립트 개 발을 위해서 선정된 장소를 방문하여, 대화 상황을 직접 관찰 하고 종사자(예: 미용사, 은행원, 미소지기, 편의점 아르바이트 생)와 인터뷰를 실시하였다. 이를 토대로 스크립트 제작에 필요 한 어휘와 문장을 수집하였으며, 핵심 어휘와 대화 문장으로 구성된 스크립트 대본을 제작하였다.

\section{3단계: 스크립트 타당성 검증}

스크립트의 대본에서 사용된 어휘와 문장의 적절성을 확인 하기 위해서, 대학에 재학 중이거나 직장에 근무하고 있는 20대 건청 성인 35 명 $(\mathrm{M}=23.2, \mathrm{SD}=0.65)$ 에게 일상생활 타당도 검 증을 실시하였다. 대상자는 스크립트의 어휘와 대화 문장을 읽 고, 4점 Likert 척도를 이용하여 친숙도(1점: 매우 낮다, 2점: 낮 다, 3점: 높다, 4점: 매우 높다)와 필요도(1점: 매우 필요하지 않 다, 2점: 필요하지 않다, 3점: 필요하다, 4점: 매우 필요하다)를 평정하였다.

\section{4단계: 인공와우이식 성인에게 중재 적용을 통한 스크립트 기반의 도구 예비평가}

본 연구에서는 스크립트 기반의 도구에 대한 예비평가를 위 해서 부산에 거주하는 20 대 인공와우이식 성인 3명을 대상으 로 중재 적용을 시행하였다. 중재를 실시하기 전에 인공와우이 식 성인 1명에게 모의 중재를 실시하여, 실제 중재 절차를 보완 하는 과정을 거쳤다. 대상자는 어음청각검사(Korean Speech Audiometry, KSA) (Lee et al., 2010)에서 20 50\%의 단어인지

Table 2. Frequency (\%) of script for developing auditory training materials in congenitally deaf young adults with cochlear implants $(n=20)$

\begin{tabular}{|c|c|c|}
\hline Category & Situation of script & Frequency $(\%)$ \\
\hline \multirow[t]{7}{*}{ Places where people frequently visit* } & Public transportation & $17(42.5)$ \\
\hline & Mart & $11(27.5)$ \\
\hline & Cinema & $6(15)$ \\
\hline & Café & $3(7.5)$ \\
\hline & Restaurant & $2(5)$ \\
\hline & University & $1(2.5)$ \\
\hline & Clothing store, library, karaoke, company, beauty shop, bank & $0(0)$ \\
\hline \multirow{5}{*}{$\begin{array}{l}\text { Places where people have difficulty } \\
\text { communicating }\end{array}$} & Beauty shop & $9(45)$ \\
\hline & Bank & $7(35)$ \\
\hline & Hospital & $3(15)$ \\
\hline & Clothing store & $1(5)$ \\
\hline & $\begin{array}{l}\text { Restaurant, public transportation, mart, cinema, library, company, } \\
\text { university, karaoke, café }\end{array}$ & $0(0)$ \\
\hline
\end{tabular}

*An asterisk indicates multiple answers 
도(word recognition score)를 보이며, 청력검사(Interacoustics AD629, interacoustics A/S, Assens, Denmark)에서 교정청력 (aided threshold)이 $40 \mathrm{~dB} \mathrm{HL}$ 미만이고, 인공와우를 이식하 여 1년 이상 사용하고 정기적인 매핑(mapping)을 실시하고 아 동기에 청능훈련을 받았음에도 의사소통에 어려움을 겪고 있 는 대상자로 선정하였다. 그리고 난청인의 보장구 유형과 연령 에 따라 청능훈련에 대한 요구도와 일상생활 패턴이 달라질 수 있는 점을 고려하여, 코클리어 사(Cochlear Ltd., Sydney, Australia)의 뉴클리어스 인공와우(Necleus cochlear implant)를 착 용한 20대 난청 성인을 대상자로 선정하였다. 대상자의 세부적 인 정보를 요약하면 다음과 같다(Table 3).

\section{인공와우이식 성인 $\mathrm{A}$ 의 정보}

대상자 $\mathrm{A}$ 는 만 23세로, 2세경 난청 진단을 받고 좌측에 보청 기를 착용했으며, 19 세에 우측에 인공와우이식을 받았다. 7세에 청각장애학교에서 특수교육을 받았으며, 8세부터는 일반학교 도움반에서 교육을 받았다. 2014년 9월(만 20세)부터 현재까지 $\bigcirc$ 대학 언어임상센터에서 주 2회 청능훈련을 받고 있다. 보기 가 없는 조건에서 실시한 KSA (Lee et al., 2010)의 단어인지도 는 $25 \%$ 로 나타났으며, 수용 및 표현 어휘력 검사(Receptive and Expressive Vocabulary Test-Receptive, REVT-R) (Kim et al., 2009)에서 수용 어휘의 등가 연령이 만 14 세로 나타났다. 아동용 발음평가(Assessment of Articulation and Phonology for Children, APAC) (Kim et al., 2007)에서 자음정확도는 $80.0 \%$ 였으나, 낮은말 명료도로 인하여 건청 성인이 의사소통 하는 데 어려움이 크다고 하였다.

\section{인공와우이식 성인 $\mathrm{B}$ 의 정보}

대상자 $\mathrm{B}$ 는 만 22세로, 8세경 좌측에 첫 번째 인공와우이식 을 받았다. 이후, 만 20세에 우측에 두 번째 인공와우이식을 받
았으며, 현재 대학교에 재학 중이다. 보기가 없는 조건에서의 KSA (Lee et al., 2010)의 단어인지도는 50\%였으며, REVT-R (Kim et al., 2007)에서 수용 어휘의 등가 연령은 9세 6개월에 서 11개월로 나타났다. APAC (Kim et al., 2007)에서 자음정확 도가 $80.0 \%$ 였다. 본 대상자는 현재 대학교에 재학 중이며, 낮은 말명료도로 인해 의사소통에 어려움을 겪고 있다고 하였다.

\section{인공와우이식 성인 $\mathrm{C}$ 의 정보}

대상자 $\mathrm{C}$ 는 만 25세로 현재 직장생활을 하고 있으며, 5세경 좌측에 인공와우이식을 받았다. REVT-R (Kim et al., 2009)에 서 수용 어휘의 등가 연령이 9 세 6 개월에서 11 개월이었으며, $\mathrm{APAC}$ (Kim et al., 2007)에서 자음정확도가 80.0\%였다. 보기가 없는 조건에서 KSA (Lee et al., 2010)의 단어인지도는 $27 \%$ 였 다. 본 대상자는 인공와우이식 상태임에도 불구하고 낮은 말지 각을 호소하고 있으며, 발음 시 낮은 말명료도로 인하여 직장 동료와의 의사소통에 어려움을 겪고 있다고 하였다.

\section{중재 절차}

중재 실시 전, 연구자는 대상자에게 연구 목적, 중재 도구 및 절차, 회기별 소요 시간 등과 관련된 설명을 충분히 하였다. 이 때, 연구자는 대상자에게 중재 중에 언제든지 연구에 참여하는 것을 중단할 수 있다는 것을 숙지시켰으며, 연구에 동의한 대상 자에 한해서 실험에 참여하도록 하였다. 본 중재에서는 개발한 스크립트 기반의 청능훈련 도구를 사용하였으며, $\bigcirc \bigcirc$ 대학 언 어임상센터에서 대상자에게 개별적으로 청능훈련을 진행하였 다. 대상자는 4주 동안 일주일에 2회씩 청능훈련 회기(40분)에 참여하였다. 중재는 제 1 연구자에 의해서 회기마다 직접 중재하 였으며, 제 2 연구자가 스크립트에서 사회 역할극 상황에 참여하 거나 대상자의 반응을 기록하였다.

청능훈련은 '어휘 듣기 $\rightarrow$ 스크립트 대본 연습 $\rightarrow$ 스크립트

Table 3. General information of three adults with Cls

\begin{tabular}{lccc}
\hline \multicolumn{1}{c}{ Information } & Subject A & Subject B & Subject C \\
\hline Age(sex) & $23(\mathrm{M})$ & $22(\mathrm{~F})$ & $25(\mathrm{M})$ \\
CI fitting ears & Rt. & Both & Lt. \\
Age at the first implantation (years) & 19 & Lt. 8 / Rt. 20 & 5 \\
Daily use of CI (hours) & 7 & 11 & 10 \\
Duration of an implant use (years) & 4 & 14 & 20 \\
Unaided threshold in PTA (dB) & Rt. scale-out / Lt. 105 & Rt. scale-out / Lt. 108 & AU scale-out \\
Aided threshold (dB) & 28 & 29 & 28 \\
Aided WRS* at conversational level (\%) & 25 & 50 & 27 \\
PCC $^{\dagger}$ (\%) & 80 & 80 & 80 \\
Receptive vocabulary scores $^{*}$ (EA) & $14 ; 0$ & $9 ; 6-9 ; 11$ & $9 ; 6-9 ; 11$ \\
\hline
\end{tabular}

*Korean Speech Audiometry (Lee et al., 2010), ${ }^{\dagger}$ Assessment of Articulation and Phonology for Children (Kim et al., 2007), ${ }^{\ddagger}$ Receptive and Expressive Vocabulary Test-Receptive (Kim et al., 2009). M: male, F: female, CI: cochlear implant, PTA: pure tone audiometry, AU: aures unites, WRS: word recognition score, PCC: percentage of consonants correct, EA: equivalent age, Rt: right, Lt: left 
역할극 수행'의 단계로 진행하였다. 청능훈련은 조용한 공간에 서 진행되었으며, 중재자는 듣기에 편한 일상 대화의 말소리 강 도인 약 $60 \mathrm{~dB} \mathrm{SPL}$ 수준으로 단어와 문장을 대상자에게 육성 으로 들려주었다. 어휘 듣기 단계에서는 연구자가 대상자의 귀 에서 약 $1 \mathrm{~m}$ 의 거리에서 시각 단서 없이 어휘를 들려주었으며, 목표 어휘를 따라 말하거나 받아 적도록 하여 대상자가 목표 어휘를 정확하게 들었는지 확인하였다. 스크립트 대본 연습 단 계에서는 대상자에게 스크립트와 관련된 그림을 제시하였으며, 연구자의 질문에 따라 대상자가 적절한 그림을 선택하면서 대 답하도록 하였다. 스크립트 역할극 수행 단계에서는 연구자와 대상자가 자유롭게 대화를 하면서 스크립트 상황에 참여하였 다. 말지각이 매우 부진한 인공와우이식 성인 $\mathrm{A}$ 의 경우, '어휘 듣기 $\rightarrow$ 스크립트 맥락 이해 $\rightarrow$ 스크립트 대본 연습 $\rightarrow$ 스크립 트 역할극 수행'의 네 가지 단계로 진행하여, 좀 더 쉽게 스크립 트 대본 연습과 역할극을 수행할 수 있도록 하였다. 스크립트 맥락 이해 단계에서는 대상자에게 스크립트와 관련된 상황 맥 락에 대해 시각 단서(예: 글, 제스처 등)로 충분히 이해할 수 있 도록 한 후에 세부적인 스크립트를 시연하였다.

\section{사전-사후검사}

인공와우이식 성인을 대상으로 한 스크립트 기반의 청능훈 련의 중재 효과를 살펴보기 위해서, 대상자에게 중재 전과 후 에 말지각검사와 의사소통 만족도 설문조사를 실시하였다. $\mathrm{KSA}$ (Lee et al., 2010)의 단어인지도와 문장인지도 검사를 사 용하여 대상자의 말지각을 평가하였다. 이때, 연구자는 대상자 가 듣기에 편한 일상대화의 말소리 강도인 약 $60 \mathrm{~dB} \mathrm{SPL}$ 수준 으로 발화를 들려주었다. 의사소통 만족도를 측정하기 위해서, Lee(2016)의 연구를 참고하되, 대상자의 연령을 고려하여 의사 소통 능력(3문항, 점수 범위: 3 15점), 청각적 수행력(5문항, 점 수 범위: 5 20점), 의사소통 부담감(5문항, 점수 범위: 5 20점) 영역으로 구분하여 총 13 개의 문항으로 구성된 설문지를 개발 하였다(Table 4, Appendix 2). 각 문항은 4점 Likert 척도(1점: 매우 그렇지 않다, 2점: 그렇지 않다, 3점: 그렇다, 4점: 매우 그렇 다)로 응답하도록 하였으며, 의사소통 만족도 점수는 총 점수 (범위: 13 52점)와 영역별 점수로 구분하여 산출하였다.

\section{RESULTS}

\section{스크립트 타당성 검증 결과}

스크립트 타당성을 검증한 결과, 스크립트 내 어휘와 문장의 친숙도 및 필요도가 모두 높게 나타났다(Figure 1). 어휘 친숙 도는 '매우 높다'가 $46.6 \%$, '높다'가 $47 \%$ 로, 어휘 필요도는 '매우 높다'가 $45.8 \%$, '높다'가 $48.4 \%$ 로 평정되었다. 문장에 대한 친숙 도는 '매우 높다'가 $46.6 \%$, '높다'가 $53.0 \%$, 문장 필요도는 '매우 높다'가 $38.8 \%$, '높다'가 $56.4 \%$ 로 나타났다. 친숙도와 필요도가 높게 평정된 어휘와 문장만으로 스크립트 대본을 구성하였으 며, 모의 중재를 인공와우이식 성인(n = 1)에게 실시하여 스크 립트 어휘와 문장에 대한 의견을 수렴하여 스크립트를 최종적 으로 완성하였다.

\section{스크립트 기반의 청능훈련 도구 개발}

본 연구에서는 '청능 20 분'이라는 교재의 형태로 스크립트 기 반의 청능훈련 도구를 제작하였다. 임상에서 겪고 있는 곤란한 상황들을 반영하여, 전문가는 대상자의 회기별 수행력을 바로 기입하고 즉각적인 피드백을 진행할 수 있도록 하였다. 대상자 는 가정 내에서 피드백을 살펴봄으로써 한 번 더 지도가 이루 어지고, 중재 시간 외에 도구를 활용하여 다양한 사람들과 청 능훈련이 가능하도록 하였다. 도구는 대상자가 휴대하기 간편 하도록 디자인하였으며, 타당성 검증을 마친 어휘와 문장을 내 용으로 구성하였다. 난청 성인이 본인의 청각적 수행력 및 의사 소통 능력에 따라 다양한 난이도로 청능훈련에 참여할 수 있 도록, 어휘와 문장을 구분하여 구성하였으며, 어휘는 빈도를 기 준으로 명사와 동사를 범주별로 표로 제시하였다. 문장은 맥락 의 이해를 돕고자 장소와 관련된 인물의 그림을 삽입하였으며, 상황에 따른 문장과 부수 어휘를 목록화하여 제시하였다. 스크 립트의 세부적인 상황을 분류하여 난청 성인이 전체적인 문맥 의 흐름이나 특정 문맥을 문장 수준에서 훈련할 수 있도록 하 였으며, 다양한 의사소통 상황에 적극적으로 참여할 수 있도록 돌발 상황을 추가하였다. 또한, 도구에 '세부 양식란'을 추가하 여, 전문가나 본인이 수행 수준, 오반응, 특이사항 등을 추가적 으로 기록할 수 있도록 하였다(Figure 2).

Table 4. Questionnaires and their structures

\begin{tabular}{llc}
\hline \multicolumn{1}{c}{ Questionnaire } & Content & No. of items \\
\hline Communication abilities & $\begin{array}{c}\text { Comparison of communication satisfaction before and after 1 month, oral communication } \\
\text { skills, communication effort }\end{array}$ \\
& $\begin{array}{l}\text { Auditory performance in various situations, familiarity with communication partners and } \\
\text { situations }\end{array}$ & 5 \\
Communication burden & $\begin{array}{l}\text { Psychological pressure by communicating with others (frustration, burden, pressure, } \\
\text { dependence, confidence) }\end{array}$ \\
\hline
\end{tabular}




\section{중재 적용 연구를 통한 스크립트 기반의 훈련 도구 예비평가}

\section{단어 및 문장인지검사 점수 변화}

스크립트 기반의 청능훈련의 전과 후에 실시한 단어인지도 의 평균 점수를 살펴보면, 중재 전의 점수는 $48.32 \%(\mathrm{SD}=$ $38.34)$, 중재 후의 점수는 $55.0 \%(\mathrm{SD}=35.00)$ 였다. 문장인지도 에서는 중재 전의 평균 점수는 $23.32 \%(\mathrm{SD}=20.82)$, 중재 후의 평균 점수는 $25.00 \%(\mathrm{SD}=21.78)$ 였다. 단어인지도 결과를 살펴 보면, 대상자 $\mathrm{A}$ 와 $\mathrm{C}$ 는 중재 후에 단어인지도가 10 20\% 정도 향상되었으며, 대상자 $\mathrm{B}$ 는 중재 전과 후의 단어인지도는 변화 가 없었다. 문장인지도 결과를 살펴보면, 대상자 A, B, C 모두 중재 후의 문장인지도가 중재 전에 비해 향상 정도가 미비하였 다(Figure 3).

\section{의사소통 만족도 설문조사 결과}

대상자들이 주관적으로 중재 전과 후에 평정한 의사소통 능 력, 청각적 수행력, 의사소통 부담감의 세 영역에 대한 합산 점 수로 살펴본 의사소통 만족도에 대한 총 점수는 중재 전의 점 수는 30.00점 $(\mathrm{SD}=7.21)$, 중재 후의 총 점수는 38.00점 $(\mathrm{SD}=$ 9.54)이었다. 영역별 점수를 살펴보면, 의사소통 능력은 중재 전 의 총 점수가 5.32 점 $(\mathrm{SD}=2.52)$, 중재 후의 총 점수가 8.00점 $(\mathrm{SD}=2.65)$, 청각적 수행력은 중재 전의 총 점수가 12.00 점 $(\mathrm{SD}=$ $2.65)$, 중재 후의 총 점수는 14.67 점 $(\mathrm{SD}=4.50)$ 으로 나타났다. 의사소통 부담감에 대한 중재 전의 총 점수는 12.67 점 $(\mathrm{SD}=$ 2.52), 중재 후의 총 점수는 15.32 점( $\mathrm{SD}=3.20)$ 으로 나타났다. 단기간의 스크립트 중재 후에 실시한 대상자의 주관적인 변화 는 의사소통 능력, 청각적 수행력, 의사소통 부담감에서 상승되 었으나, 그 상승 정도는 작았다(Figure 4).
Figure 1. Results of the questionnaires for verification of core vocabulary and sentences in the scripts of the auditory training. A: Familiarity of words. B: Need of words. C: Familiarity of scripts. D: Need of script.

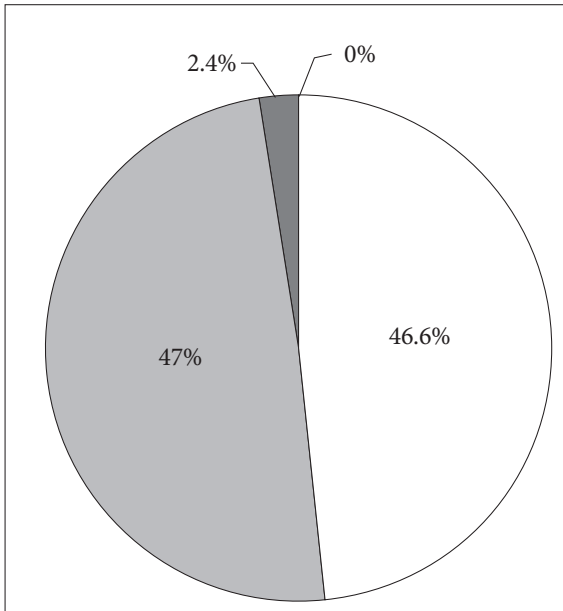

A $\square$ Very high $\square$ High $\square$ Low

Very low

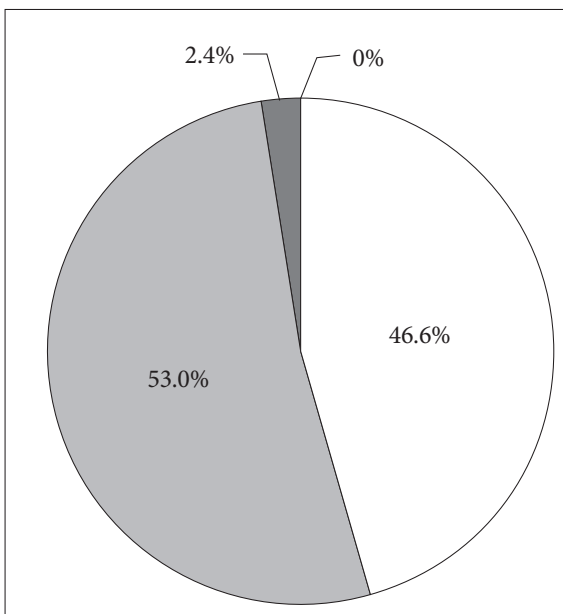

C $\square$ Very high $\square$ High $\square$ Low

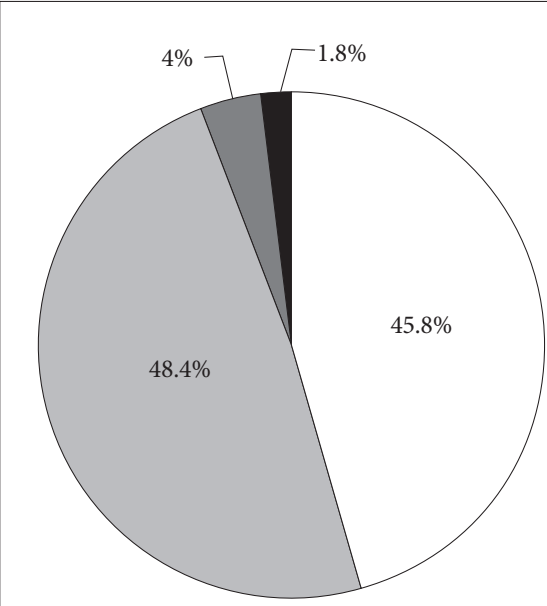

B $\square$ Very high $\square$ High $\square$ Low Very low

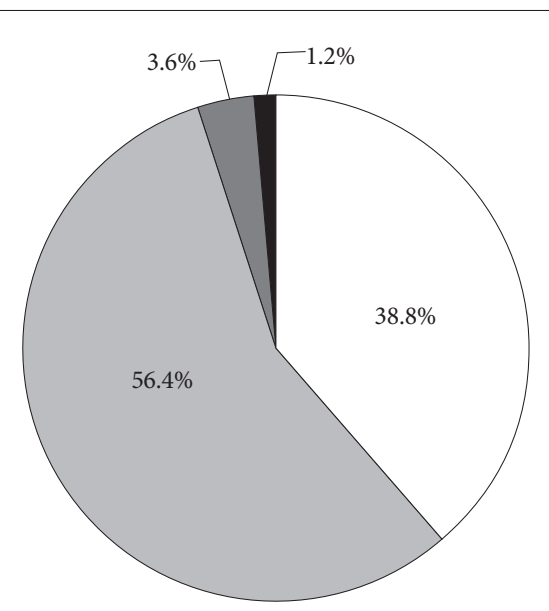

D $\square$ Very high $\square$ High $\square$ Low 

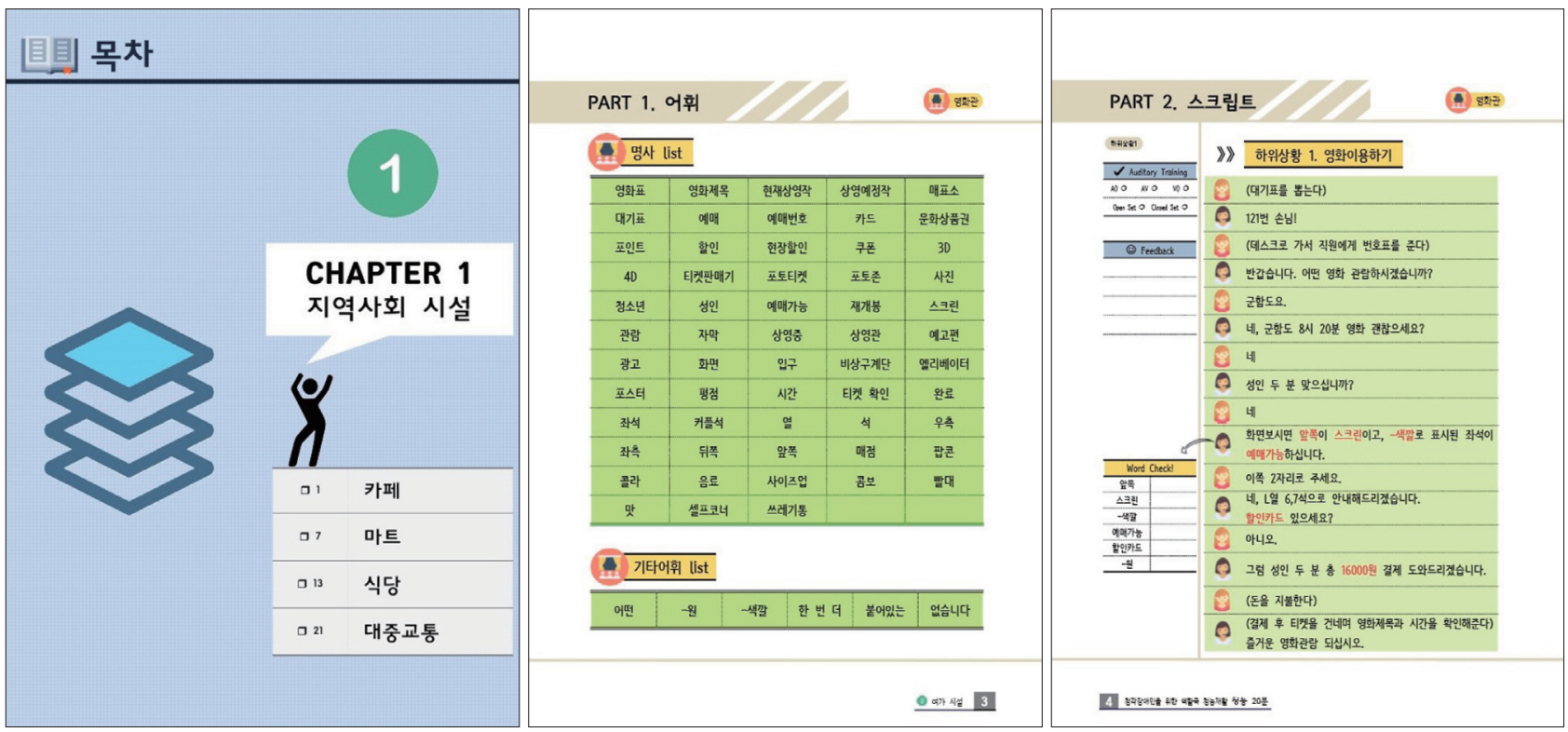

Figure 2. Examples of script-based auditory training materials.
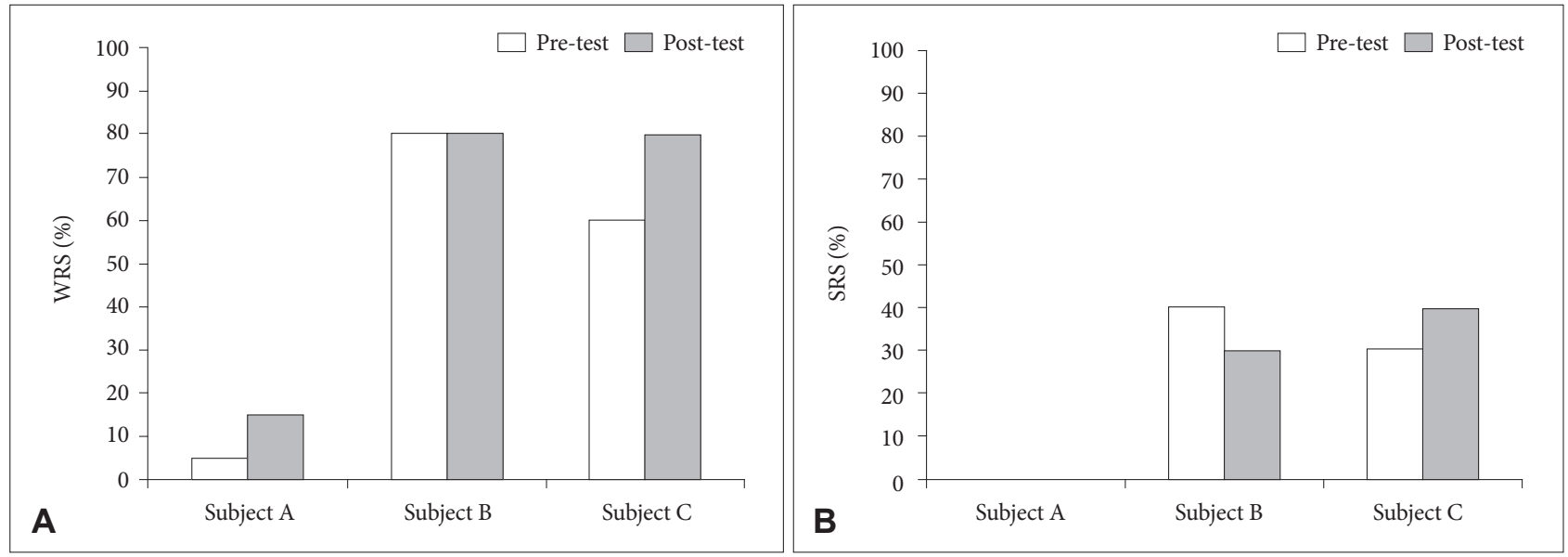

Figure 3. Comparisons of WRS and SRS before and after the script-based auditory training. A: WRS in each adult with Cls. B: SRS in each adult with Cls. WRS: word recognition score, SRS: sentence recognition score, Cls: cochlear implants.

\section{DISCUSSIONS}

난청 성인의 원활한 의사소통과 원활한 사회 참여를 위해서 는 정확한 청력검사, 적절한 보장구 조절 및 착용, 청능훈련이 필요하다. 최근에는 난청 성인에게 실시한 청능훈련이 말지각 향상과 난청지수 감소에 긍정적인 효과가 있다고 보고되면서, 다양한 청능훈련 도구를 개발하여 난청 성인의 청능훈련에 대 한 흥미와 몰입도를 증가시키고자 방법을 모색하고 있다(Ahn \& Lee, 2016; Baek \& Lee, 2016; Chang \& Lee, 2016; Kim \& Bahng, 2017; Lim \& Bahng, 2016). 본 연구에서는 의사소통 능력이 낮은 인공와우이식 선천성 농 성인의 기능적인 의사소 통에 초점을 둔 스크립트 기반의 청능훈련 도구를 개발하고,
중재를 적용하여 효과를 확인하고자 하였다.

본 연구에서 스크립트를 이용한 청능훈련의 효과를 인공와 우이식 선천성 농 성인의 중재 전과 후의 말지각 변화로 살펴 본 결과, 중재 후의 단어인지도와 문장인지도의 평균 점수가 중 재 전에 비해서 향상되었으나, 문장 수준에서의 말지각 향상은 미비하였다. 이러한 결과는 중재에 참여한 대상자의 수, 대상자 특성, 중재 기간, 중재 내용에 영향을 받은 것으로 생각한다. 본 연구에서는 선천성 농으로 인해 인공와우이식을 받은 성인 3 명 을 대상으로 하였으며, 이들은 연령 및 인공와우 사용 기간을 고려할 때 말지각 발달이 정체기(plateau)에 도달하여 단기간의 중재로 말지각 향상이 즉각적으로 성취되기 힘든 대상자였을 것으로 생각한다. 즉, 본 연구에 참여한 대상자들은 말지각 외 
Figure 4. Comparisons of subjective communicative satisfaction for adults with $\mathrm{Cls}$ before and after script-based auditory training. A: Total ratings of communicative satisfaction for adults with Cls. B: Ratings of comprehensive communication abilities for adults with Cls. C: Ratings of auditory performance for adults with Cls. D: Ratings of communication burden for adults with Cls. Cls: cochlear implants.
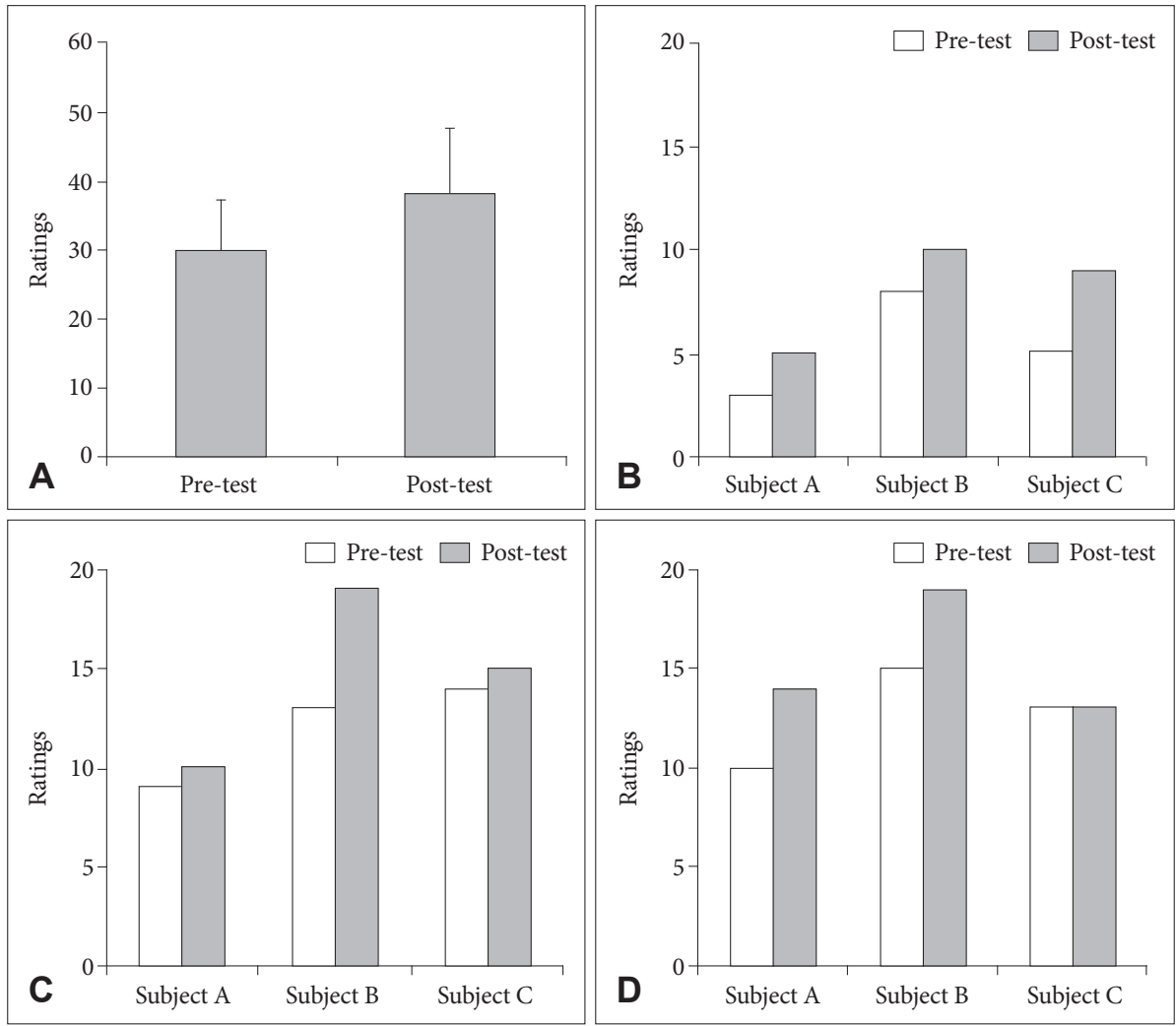

에 난청지수 감소, 의사소통 만족도 등과 같은 영역에서 주관적 인 지각과 능력 변화에 초점을 두어 청능훈련에 참여하도록 독 려하고 긍정적인 지원을 제공해야 할 대상자라고 할 수 있겠다. 그리고 본 연구에서 대상자에게 제공한 중재 기간은 4주에 불 과하여, 문장 수준의 말지각 향상까지 기대하기에는 무리가 있 었던 것으로 판단된다. 또한, 중재의 내용이 일상생활에서의 대 화 맥락을 이해하고 필요한 문장에 대해 친숙해질 수 있는 경 험을 제공하는 데 초점을 두었기 때문에, 말지각에서의 효과는 미비했던 것으로 생각된다.

스크립트 기반의 청능훈련의 효과를 주관적인 의사소통 만 족도 측면에서 살펴보면, 중재 후의 의사소통 만족도 총점이 중 재 전에 비해서 상승의 폭은 적었지만 긍정적인 영향을 미치는 것으로 나타났다. 본 연구에서 사용한 스크립트는 20대 난청 성인의 일상생활 상황에 초점을 맞춘 기능적 접근법에 근거하 여 개발되었으므로, 중재 기간 동안 난청 성인이 지역사회의 구 성원으로서 마주하는 다양한 의사소통 상황에 필요한 어휘와 문장을 연습할 수 있는 기회를 제공하였다. 그리고 도구에는 청능훈련 양식, 피드백, 자극 단어 반응 등의 정보를 포함시켜 서 개별적인 훈련 외에 가정에서도 친숙한 사람들과 반복적으 로 훈련할 수 있도록 하였다. 특히, 본 연구에 참여한 인공와우 이식 성인의 말지각 능력이 부진한 것을 고려해 볼 때, 이들이 의사소통하기에 힘든 특정 상황과 관련된 사건들의 관계 이해
에 초점을 맞추어 활동을 진행하는 스크립트 기반의 청능훈련 이 의사소통 만족도 변화에 긍정적인 영향을 미쳤을 것으로 생 각된다. Lim \& Bahng(2016)의 연구에서도 보청기를 착용한 난청 성인을 대상으로 이야기 기반의 청능훈련 도구를 개발, 적용하여 어음인지력과 청능훈련의 주관적인 만족도가 향상되 었다고 보고한 바 있다. 이러한 결과들은 스크립트를 이용한 하향식의 청능훈련이 난청 성인의 의사소통 능력 만족감, 청각 적 수행력, 청능훈련에 대한 만족감 향상 등에 긍정적인 영향 을 미칠 수 있음을 시사한다. 그리고 본 연구에서 대상자에게 스크립트 기반의 청능훈련에 대한 인터뷰를 실시한 결과, 청능 훈련이 일상생활과 관련된 활동으로 진행되어 지루하지 않았으 며, 중재에서 제공한 스크립트 상황이 대화 상대자와 적절하게 의사소통을 하기에는 쉽지 않은 도전적인 과제였다고 언급하였 다. 그래서 향후 스크립트로 난청 성인의 청능훈련을 진행할 때 는 대상자의 친숙성과 필요성에 맞추어 스크립트를 구성하되, 대상자의 의사소통 능력을 고려하여 난이도를 다양하게 할 필 요가 있을 것으로 생각한다.

의사소통장애를 가진 성인을 대상으로 적용한 선행연구는 Goldberg et al.(2012)이 실어증 성인을 대상으로 대화 스크립 트를 이용하여 의사소통 증진을 위한 훈련 결과, 기능적인 대 화의 정확도, 문법 형태소 사용, 말 속도 등에서 개선 효과가 있 었다. Choi \& Yu(2007)가 중증 브로카 실어증을 대상으로 보 
완대체 의사소통에 스크립트를 접목시켜 중재를 실시한 결과 중재 후에 의사소통 능력이 향상되었으며, Jeong(2009)이 브로 카 실어증을 대상으로 스크립트 중재를 실시한 결과에서도 용언 사용의 능력이 향상되었다. 스크립트를 활용한 다수의 선행연구 (Cho \& Kim, 2014; Kim et al., 2011; Kim \& Choi, 2013; Lee et al., 2013; Shim, 2012)에서는 지적장애, 자폐 스펙트럼 장애, 청각 장애 등과 같이 장애 유형과 무관하게 스크립트를 접목한 중재 가 아동의 의사소통 능력 향상에 긍정적인 영향을 미친다고 보 고하고 있다. 따라서, 스크립트를 이용하여 신경언어장애군 성 인과 여러 장애 유형의 아동에게 스크립트를 적용하여 의사소 통 능력의 향상을 보고하고 있는 다수의 선행연구는 난청 성인 에게도 유용한 청능훈련 도구로 적용될 수 있으며, 기능적인 청능훈련 접근법이 의사소통 능력이 제한적인 인공와우이식 선천성 농 성인의 의사소통 능력 증진을 목적으로 다양하게 사 용될 수 있음을 시사한다.

본 연구는 스크립트 기반의 청능훈련 도구가 인공와우이식 선천성 농 성인의 전반적인 의사소통 만족감 측면에서 효과를 확인하였다. 이러한 결과는 다양한 청능훈련 도구 개발이 난청 성인의 의사소통 능력 향상에 도움을 준다는 것을 의미하겠다. 하지만, 본 연구에서는 의사소통 능력이 제한적인 인공와우이 식 선천성 농 성인을 대상으로 한 스크립트의 중재 효과가 객 관적인 평가 결과에서는 미비하여, 청능재활 적용에 대한 탐색 을 충분히 하지 못한 제한점을 지니고 있다. 이 외에도 다음과 같은 제한점이 있으므로, 향후 연구에서는 이를 보완한 연구가 필요할 것으로 보인다. 첫째, 본 연구에서는 20 30대의 난청 성 인에 초점을 맞추어서 스크립트 청능훈련 도구를 개발하고 해 당 연령의 난청 성인에게 중재를 적용한 것으로, 난청 노인에게 적용하기 위한 적절한 스크립트의 개발이 필요할 것으로 생각 된다. 둘째, 단일 실험 집단으로 4주 동안 총 8 회기의 중재가 진 행되었으며, 연구 효과의 신뢰성을 높이기 위해서는 장기적인 중재 진행이 필요할 것으로 생각한다. 셋째, 스크립트 기반 훈련 도구는 사회적 맥락을 기반한 것으로, 사회적 맥락이 일어나는 환경의 소음 유형, 강도, 신호대잡음비를 고려하여 각 상황에 적합한 청능훈련 도구 개발이 필요할 것으로 생각된다. 따라서, 후속 연구에서는 다양한 연령대를 대상으로 장기간의 청능훈 련을 실시하고 표준화된 설문지를 사용하여 중재 효과를 평가 할 필요가 있으며, 대상자 수를 늘리고 통제집단을 설정함으로 써 두 집단 간의 수행력 비교를 통하여 청능훈련의 효과에 대 한 정규성을 높일 수 있는 자료를 수집해야 할 것이다. 또한, 각 스크립트 상황에 따른 신호대잡음비를 고려한 프로그램을 개 발하여, 일상생활과 유사한 상황에서의 청능훈련이 가능하도 록 할 필요가 있겠다.
중심 단어 : 스크립트 기반의 청능훈련·선천성 농 성인·인공와 우이식.

\section{Ethical Statement}

The authors explained the purpose and procedure of this study to the participants, and obtained the consent of each subject who was willing to participate in this study.

\section{Acknowledgments}

The authors would like to thank to all participants who attended in this study.

\section{Declaration of Conflicting Interests}

There are no conflict interests.

\section{Funding}

N/A

\section{REFERENCES}

Ahn, P. \& Lee, K. (2016). Development of environmental sounds for auditory training. Audiology and Speech Research, 12(2), 82-88.

Baek, S. S. \& Lee, J. H. (2016). Development of crossword puzzles for auditory training. Audiology and Speech Research, 12(2), 103-108.

Blamey, P. J. \& Alcántara, J. I. (1994). Research in auditory training. Journal of the Academy of Rehabilitative Audiology, 27(Mono Suppl), 161-191.

Burk, M. H., Humes, L. E., Amos, N. E., \& Strauser, L. E. (2006). Effect of training on word-recognition performance in noise for young normalhearing and older hearing-impaired listeners. Ear and Hearing, 27(3), 263-278.

Chang, S. \& Lee, J. (2016). Development of auditory training tool for adults using sentences. Audiology and Speech Research, 12(2), 89-96.

Cho, S. J., Hwang, B. M., \& Yoo, J. Y. (2011). Analyzing of research trends on cochlear implant in Korea: Mainly focused on researches since 2000. Audiology and Speech Research, 7(2), 206-18.

Cho, S. Y. \& Kim, J. Y. (2014). The effect of AAC intervention based on script activities for the students with severe and multiple disabilities. AAC Research and Practice, 2(1), 23-47.

Choi, Y. M., Kim, H. H., Jeong, S. W., \& Kim, L. S. (2018). Interpersonal competence in college students with cochlear implants: A preliminary study. Korean Journal of Otorhinolaryngology-Head and Neck Surgery, 61(7), 341-348.

Choi, Y. S. \& Yoo, J. Y. (2007). Effects of cheap talk on improving communicative ability in severe Broca's aphasics. Speech Sciences, 14(4), 233249.

Fu, Q. J., Galvin, J., Wang, X., \& Nogaki, G. (2005). Moderate auditory training can improve speech performance of adult cochlear implant patients. Acoustics Research Letters Online, 6(3), 106-111.

Goldberg, S., Haley, K. L., \& Jacks, A. (2012). Script training and generalization for people with aphasia. American Journal of Speech-Language Pathology, 21(3), 222-238.

Jeong, M. S. (2009). The effect script activity influected word by patients with a Broca's aphasia (Unpublished master's thesis). Daegu University, Gyeongsan.

Kim, A. H., Kim, U. J., \& Pyo, S. R. (2011). The effect of scripted, synthetic phonics instruction program on word identification of children with reading disabilities. Journal of Special Education: Theory and Practice, 12(3), 613-638

Kim, K., Kim, J., Kim, H., Bahng, J., Lee, K., Lee, J., et al. (2014). Introduction to Audiology. Seoul: Hakjisa.

Kim, M. J., Pae, S., \& Park, C. (2007). Assessment of Phonology and Articulation for Children (APAC). Incheon: Human Brain Research \& Consulting Co. 
Kim, N. K. \& Bahng, J. (2017). Development of story based auditory training tool evaluation of the training efficacy for adult hearing impaired listeners. Audiology and Speech Research, 13(2), 133-140.

Kim, S. Y. \& Choi, Y. H. (2013). The effects of conversational turn-taking using a script of cooking activities on the social-communication of preschooler with developmental delays. Korean Journal of Early Childhood Special Education, 13(1), 121-144.

Kim, Y. T. (2014). Assessment and Treatment of Language Disorders in Children. (2nd ed.). Seoul: Hakjisa.

Kim, Y. T., Hong, G. H., Kim, K. H., Jang, H. S., \& Lee, J. Y. (2009). Receptive and Expressive Vocabulary Test (REVT). Seoul: Seoul Community Rehabilitation Center.

Lee, G. H. (2008). The effect of script activity on naming performance in children with hearing impairment (Unpublished Master's thesis). Dankook University, Cheonan.

Lee, J., Cho, S., Kim, J., Jang, H., Lim, D., Lee, K., et al. (2010). Korean Speech Audiometry (KSA). Seoul: Hakjisa.

Lee, J. E. (2016). A study on the satisfaction in auditory performance of cochlear implant users (Unpublished master's thesis). Daegu University, Gyeongsan.

Lee, J. H., Lee. S. G., \& Bahng, J. (2016). Case study of auditory training for long-term users of hearing aids with poor word recognition. Audiology and Speech Research, 12(3), 190-194.

Lee, S. G., Jung, S. I., Tark, P. K., Lee, S. B., \& Lee, Y. (2018). Quality of communication life in prelingually deafened adults with cochlear implant. Communication Sciences and Disorders, 23(2), 528-538.

Lee, S. J. (2004). The effect of script activity on improving expressive language of the children with cochlear implants (Unpublished master's thesis). Daegu University, Gyeongsan.

Lee, Y., Jeong, S. W., \& Kim, L. S. (2013). AAC intervention using a VOCA for deaf children with multiple disabilities who received cochlear implantation. International Journal of Pediatric Otorhinolaryngology, 77(12), 2008-2013.
Lee, Y. M., Sung, J. E., Park, J. M., \& Sim, H. S. (2011). Effects of listener's experience, severity of speaker's articulation, and linguistic cues on speech intelligibility in congenitally deafened adults with cochlear implants. Phonetics and Speech Sciences, 3(1), 125-134.

Lemke, U. \& Scherpiet, S. (2015). Oral communication in individuals with hearing impairment-considerations regarding attentional, cognitive and social resources. Frontiers in Psychology, 6, 998.

Lim, E. H. \& Bahng, J. (2016). Preliminary study for development of auditory training tool using story and question. Audiology and Speech Research, 12(2), 109-114.

Oh, S. H. (2016). An overview of auditory training for cochlear implant recipients. Audiology and Speech Research, 12, S47-S50.

Park, S. H. (2008). Influence of sociodramatic play by community-centered scripts on the expressive language and nonverbal communication behavior of children with intellectual disabilities (Unpublished Master's thesis). Wonkwang University, Iksan.

Shim, G. H. (2012). The effects of enhanced milieu teaching with script on communication skills of children with intellectual disabilities (Unpublished master's thesis). Yongin University, Yongin.

Song, S. M. (2008). The effect of speech in noise training on the speech perception of cochlear implanted adults (Unpublished master's thesis). Daegu University, Gyeongsan.

Statistics Korea. (2015). Factual survey of the disabled statistical information report. Daejeon: Statistics Korea.

Sweetow, R. W. \& Sabes, J. H. (2006). The need for and development of an adaptive Listening and Communication Enhancement (LACE) program. Journal of the American Academy of Audiology, 17(8), 538-558.

World Health Organization. (2018, March). Deafness and Hearing Loss. World Health Organization. Retrieved from http://www.who.int/mediacentre/factsheets/fs300/en/.

Yorkston, K. M., Bourgeois, M. S., \& Baylor, C. R. (2010). Communication and aging. Physical Medicine and Rehabilitation Clinics of North America, 21(2), 309-319. 
APPENDICES

\section{Appendix 1. 스크립트 상황 선정을 위한 설문지}

아래 문항을 잘 읽고 해당되는 곳에 표시해 주시면 됩니다.

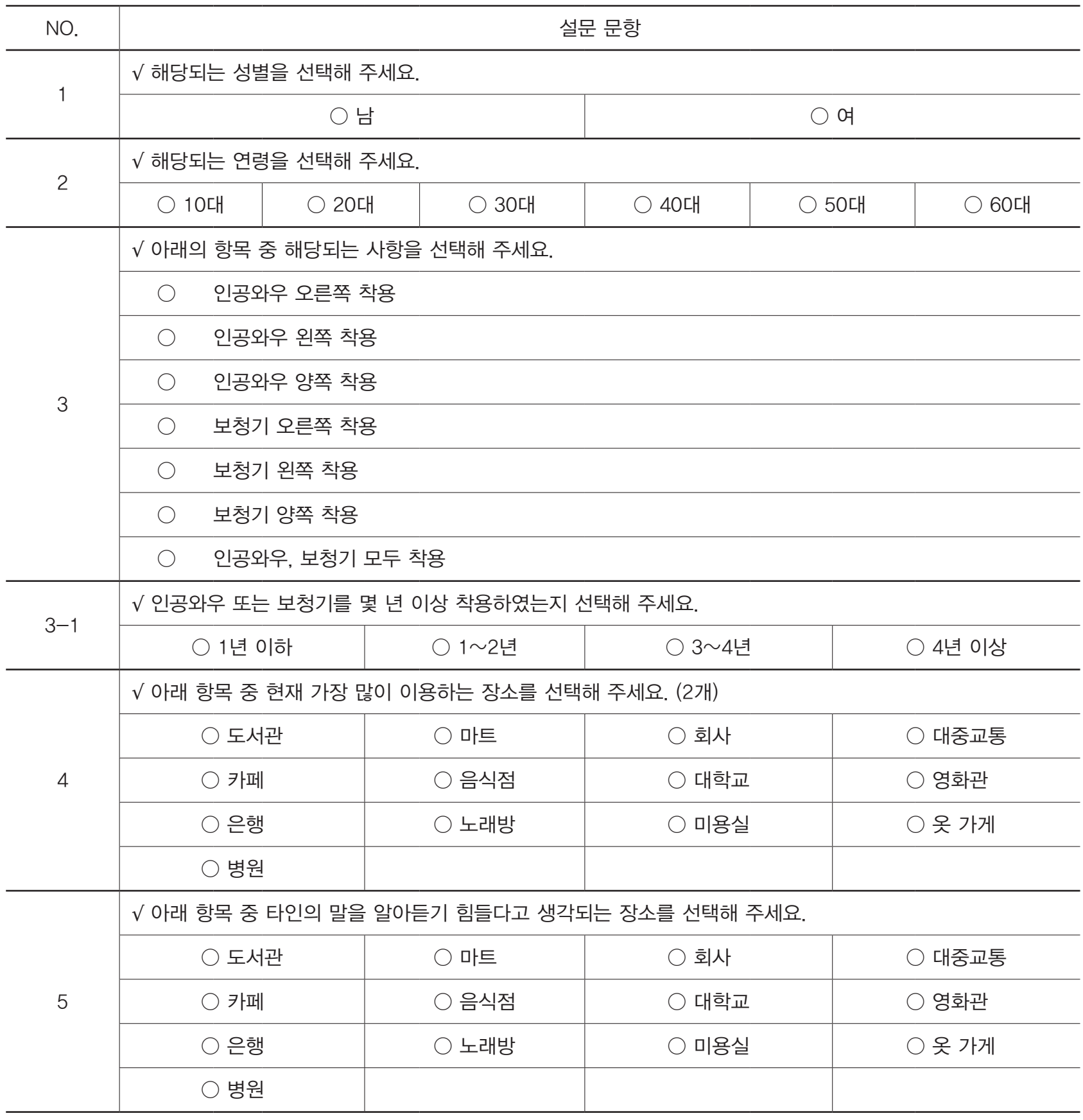




\section{Appendix 2. 인공와우이식 성인을 위한 의사소통 만족도 설문지}

\begin{tabular}{l|l|l}
\hline () 성명: & () 생년월일: & (검사일: \\
\hline
\end{tabular}

아래 문항을 잘 읽고, 해당되는 곳에 표시해 주시면 됩니다.

\begin{tabular}{|c|c|c|c|c|c|}
\hline No. & 설문 문항 & \begin{tabular}{|c|} 
매우 \\
그렇지 \\
않다
\end{tabular} & $\begin{array}{l}\text { 그렇지 } \\
\text { 않다 }\end{array}$ & 그렇다 & $\begin{array}{l}\text { 매우 } \\
\text { 그렇다 }\end{array}$ \\
\hline 1 & 다양한(은행, 마트 등) 상황에서 말을 듣고 이해할 수 있다. & (1) & (2) & (3) & (4) \\
\hline 2 & 친숙하지 않은 사람과 의사소통하는 데 어려움이 없다. & (1) & (2) & (3) & (4) \\
\hline 3 & 다른 사람이 나에게 질문을 할 때, 되묻지 않고 답할 수 있다. & (1) & (2) & (3) & (4) \\
\hline 4 & 다른 사람들이 대화하고 있을 때, 대화에 끼어들어 참여할 수 있다. & (1) & (2) & (3) & (4) \\
\hline 5 & 새로운 상황에서 듣기의 어려움 없이 잘 대처할 수 있다. & (1) & (2) & (3) & (4) \\
\hline 6 & 나의 듣기 능력으로 인해 대화가 단절되어도 좌절감을 느끼지 않는다. & (1) & (2) & (3) & (4) \\
\hline 7 & 여러 사람들과 어울릴 수 있는 낯선 장소에 가는 것에 부담감이 없다. & (1) & (2) & (3) & (4) \\
\hline 8 & 최근 1 개월 동안 압박감이 있는 상황에서 타인의 말을 이해하는 데 부담이 없었다. & (1) & (2) & (3) & (4) \\
\hline 9 & 최근 1 개월 동안 보호자(친구, 부모 등)에게 의존하지 않고 타인과 대화할 수 있었다. & (1) & (2) & (3) & (4) \\
\hline 10 & 다양한 상황에서 자신감을 가지고 적극적으로 대화에 참여한다. & (1) & (2) & (3) & (4) \\
\hline 11 & 최근 1 개월 전보다 전반적인 의사소통 능력이 향상되었다. & (1) & (2) & (3) & (4) \\
\hline 12 & 토론이나 이야기하는 것에 어려움이 없다. & (1) & (2) & (3) & (4) \\
\hline 13 & 나는 만족스러운 수준의 대화 능력을 가지고 있다. & (1) & (2) & (3) & (4) \\
\hline
\end{tabular}

